WellBeing International

WBI Studies Repository

$5-2009$

\title{
Interests and Harms in Primate Research
}

Nathan Nobis

Morehouse College

Follow this and additional works at: https://www.wellbeingintlstudiesrepository.org/acwp_arte

Part of the Animal Experimentation and Research Commons, Animal Studies Commons, and the Bioethics and Medical Ethics Commons

\section{Recommended Citation}

Nobis, N. (2009). Interests and harms in primate research. The American Journal of Bioethics, 9(5):27-29.

This material is brought to you for free and open access by WellBeing International. It has been accepted for inclusion by an authorized administrator of the WBI Studies Repository. For more information, please contact wbisr-info@wellbeingintl.org.

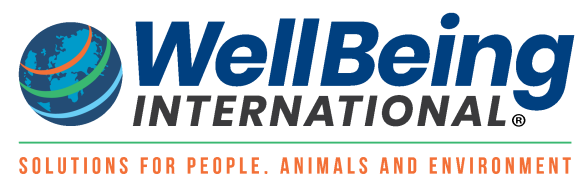




\title{
Interests and Harms in Primate Research
}

\author{
Nathan Nobis, Morehouse College
}

Sughrue and colleagues (2009) claim to offer a "balanced examination of the ethics of primate stroke research" (3). While there is some "balance" in their discussion in that they present some arguments for its moral permissibility and some arguments for its wrongness, they do not fulfill their promise to "elucidate the many ethical arguments for and against this type of research" (3, emphasis added). Perhaps they believe that greater comprehensiveness is unnecessary since they think they have successfully shown that non-human primates have no, or little, interest in not being subject to stroke experiments, are thereby not harmed by them, and therefore such experiments are morally permissible (if not obligatory, given their alleged benefits for developing stroke therapies for humans). This appears to be the main conclusion they wish to support. I will show that their moral arguments are in need of greater moral defense.

It is worthwhile to mention that the target article opens with the logically irrelevant claim that "activists" are about "Plying their trade of intimidation aimed at ending biomedical experimentation in all animals" (Sughrue et al. 2009). This is irrelevant because, first, most "activists" do not engage in any kind of "intimidation." But, second and more importantly, the behavior of anyone who engages in any intimidation, of any kind, never has bearing on the ethics of animal experimentation. By analogy, some critics of abortion 'intimidate' abortion providers, but nothing follows about the morality about abortion itself from that: abortion surely would not be morally permissible because some of its critics behave (arguably) badly. Similarly, nothing follows about the morality of animal experimentation from any activists' behavior because there is never any such connection for any moral issue. Some "activists" for animal experimentation "intimidate" some animal advocates, but that does not show that animal experimentation is wrong, as Sughrue and colleagues (2009) surely understand.

Sughrue and colleagues (2009) do not focus on ad hominem attacks on select activists, but rather engage moral arguments that they judge to be "well stated and rational" (3). They state that some arguments against animal use are "sensational" (3), but do not mention that the same is true for some arguments in favor of animal use. The single argument they consider against primate experimentation appeals to the idea of equal consideration of interests. The reasoning is this: each individual's interests deserve equal consideration to the comparable or similar interests of anyone else; primates have interests in avoiding stroke and its consequences; their interests should be given comparable weight to the similar interests of any human with a mental life similar to that primate; and, thus, since these humans' interests are given consideration enough such that they should not be experimented on for the benefit of others, consistency requires that the primates not be experimented on either.

Sughrue and colleagues (2009) acknowledge that primates have some interests, including some that are set back, violated, disrespected or compromised by stroke (and certainly are not promoted by it). They report, "monkeys with stroke may very well experience other negative emotions following stroke, such as distress at the feeling of being increasingly vulnerable, or the decreased ability to interact with their peers or to manipulate objects, including food, in their environment" (3). But they claim that "if they lead to the development of useful therapeutics for humans" (3) then "stroke experiments that take care to anticipate the specific needs of these animals are . . . [ethical]" (3). This is because, apparently, primates are thought to lack some other specific interest(s) that strokes would set back and so, as non-existent, need not be given equal consideration (or even some other less-than-equal level of consideration) to any comparable interests of any humans. 
What exactly is this interest(s)? It is not an interest in avoiding pain if Sughrue and colleagues are correct that strokes do not cause pain (3). They might also claim that it is not an interest in not suffering in certain ways, since they argue that primates do not suffer in ways that depend on abilities for abstract thought. But their argument here is dubious: "Because neither stroke nor the means of inducing the stroke is associated with substantial physical pain, for an animal to suffer during the acute period, an animal must be aware that it has a neurological deficit, and have some idea of the significance of this event" (3).

The assumption here is false: to suffer from some cause or event, one does not need to know anything about it, conceptualize it or have an idea of its significance. A human baby might suffer from malaria (or a stroke) and, of course, have no conception of the cause of her sufferings or her significance. Suffering depends on one's subjective awareness, i.e., how things seem and feel to the one who is experiencing that mental state. Abstract thought can make a difference to that-sometimes for better and sometimes for worse-but Sughrue and colleagues (2009) argument noted previously seems to imply that inducing strokes in newborn humans causes no suffering, a conclusion that many would reject, if the kind of suffering in question is taken to be necessary to deserve moral protections from such experimentation.

But not all harms are due to pain or suffering, and Sughrue and colleagues (2009) seem to argue that primates are not significantly harmed or made worse-off by given strokes and eventually killed so their brains can be studied. Potentially relevant here is their claim that, "If a nonhuman primate is able to acknowledge the existence of a hemiparesis, both at baseline and following stroke, in some meaningful way beyond that needed to alter its balance, the question we need to ask is whether they have any meaningful insight into what having a neurological deficit means, and to what degree that understanding might be compromised by the stroke itself" (3).

Sughrue and colleagues (2009) then argue that primates lack the mental capacities to acknowledge the existence of a hemiparesis and lack insight and understanding of this. If this is said because this is supposed to be a reason to think primates are not harmed by strokes-they are not made worse off than without the stroke, their well-being not lessened, and so on-this is surely false. Again, many humans, especially vulnerable ones (e.g., the very young and old) could not acknowledge or conceptualize a stroke as a stroke and lack insight and understanding, but their having had a stroke is surely bad for them, from their own point of view.

Sughrue and colleagues (2009) also claim that "because monkeys are unlikely to 'understand' stroke in the way that humans do, it follows that they do not have a similar interest in avoiding stroke" (3). While those who understand strokes might have, strictly speaking, a different interest in avoiding stroke from those who do not understand strokes (in part, because they conceptualize the event different), it does not follow that one's interest in avoiding stroke is somehow weaker than the other's: e.g., a neurologists interest in avoid stroke is different from a plumber's (and is different from a 2-year-old child's), but they all have profound interests in avoiding strokes and their consequences. And even if primates and all humans' interests are different, it does not follow that primates' interests in avoiding strokes and their consequences are not as strong as, at least, comparably minded humans. Furthermore, it does not follow that their interests are deserving of such little consideration that experimenting on them is morally permissible.

In conclusion, what Sughrue and colleagues (2009) call "human-like thought" (3) is held by a wide range of individual human beings, all of which they presumably think would be wrong to induce strokes on, without consent, for the possible benefits for others. The best strategy to begin thinking morally about animals involves thinking about these kinds of human cases and asking what moral hypotheses best explain why "vivisecting" these human beings would be wrong. The best answers here about human cases, combined with general ethical theories and moral principles that Sughrue and colleagues (2009) 
did not mention-rights theories and other deontologies, utilitarianisms and consequentialisms, ideal (Rawls-inspired) contractarianisms, virtue ethics, and other moral foundations-can have surprising implications for animal use.

What Sughrue and colleagues (2009) need to do is find and defend a morally relevant difference(s) between the ranges of human cases and the primates: in absence of a defensible proposal on that issue, their moral defense of primate use fails. They write that "any attempt to cure major complex diseases without the understanding, support, and cooperation of the majority of society's members will likely suffer due to lack of clarity and consensus" (3) This is true, but if they believe that their article provided good moral reasons to clarify why primate experiments are permissible-in the sense of providing sound or cogent moral arguments in its favor-Sughrue and colleagues, like other authors, have a lot of work left to do (Graham and Nobis 2006; Nobis 2003, 2004, 2009).

\section{REFERENCES}

Graham, D. and Nobis, N. 2006. Review of Tibor Machan's "Putting Humans First: Why We Are Nature's Favorite." Journal of Ayn Rand Studies 8: 85-104.

Nobis, N. 2003. Review of "Why Animal Experimentation Matters: The Use of Animals in Medical Research." American Journal of Bioethics 3(1): 1-2.

Nobis, N. 2004. Carl Cohen's 'kind' argument for animal rights and against human rights. Journal of Applied Philosophy 21: 43-59.

Nobis, N. 2009. Rational engagement, emotional response and the prospects for progress in animal use 'debates.' In Animal Research in Theory and Practice, ed. J. Garrett. Boston, MA: MIT. In press.

Sughrue, M., Mocco, J., Mack, W., et al. 2009. Bioethical considerations in translational research: Primate stroke. American Journal of Bioethics (AJOB Neuroscience) 9(5): 3-12. 